\title{
PELATIHAN PENGEMBANGAN KEPRIBADIAN BAGI CALON PERAWAT
}

\author{
Vera Firdaus \\ Fakultas Bisnis, Hukum Dan Ilmu Sosial, Universitas Muhammadiyah Sidoarjo \\ email: verafirdaus06@gmail.com
}

\begin{abstract}
Abstrak
Di sektor kesehatan perawat merupakan garda terdepan dalam pelayanan di rumah sakit. Kinerja perawat yang kompeten terukur dari nilai-nilai profesionalisme perawat yaitu altruism, pengembangan kepribadian diri, integritas dan self compassion. Training Personality Development ini ditujukan untuk calon perawat (prospective nurses) sebagai upaya pembinaan tentang nilai-nilai profesionalitas. Dengan demikian mahasiswa keperawatan memiliki optimisme dalam pemilihan karir sebagai perawat. Pelatihan diharapkan menjadi solusi terhadap permasalahan mahasiswa keperawatan antara lain: penurunan motivasi, kendala dalam .membangun komunikasi dan team work, kurangnya pemahaman akan pilihan karir yang menyebabkan penurunan semangat kuliah dan bahkan pengunduran diri. Training Personality Development adalah pelatihan yang memadukan metode training (pemutaran video, ceramah, simulasi games, personality test, konseling) dan materi training (manajemen, psikologi dan nilai-nilai islam). Hasil dari pengabdian masyarakat ini adalah diperolehnya pemahaman dan kesadaran mahasiswa tentang prospek karir sebagai perawat. Mahasiswa menjadi antusias dan termotivasi dalam perkuliahan. Pelatihan pengembangan kepribadian telah menumbuhkan optimisme dan kesadaran untuk mengembangkan kepribadiannya, serta meningkatkan pemahaman nilai-nilai profesionalisme sebagai perawat.
\end{abstract}

Keywords: Pelatihan, Pengembangan Kepribadian, Profesionalisme

\begin{abstract}
In the health sector, nurses are at the forefront of services in hospitals. The performance of competent nurses is measured from the values of nurse professionalism, namely altruism, personal development, integrity and self compassion. This Personality Development Training is intended for prospective nurses as an effort to develop professional values. Thus nursing students have optimism in choosing a career as a nurse. The training is expected to be a solution to the problems of nursing students, including: decreased motivation, constraints in building communication and team work, a lack of understanding of career choices which causes a decrease in enthusiasm for college and even resignation. Personality Development Training is training that combines training methods (video playback, lectures, simulation games, personality tests, counseling) and training materials (management, psychology and Islamic values). The result of this community service is the gain of understanding and awareness of students about career prospects as a nurse. Students become enthusiastic and motivated in lectures. Personality development training has fostered optimism and awareness to develop her personality, as well as improving understanding of the values of professionalism as a nurse
\end{abstract}

Keywords: Training, Personality Develompment, Profesionalism 


\section{PENDAHULUAN}

Industri pelayanan kesehatan merupakan salah satu jenis industri yang perkembangannya relatif stabil dibandingkan jenis industri lainnya. Nilai investasi asing di sektor kesehatan Indonesia melonjak tajam, dengan total investasi industri farmasi pada periode 2014-2015 adalah Rp.2,6 Triliyun (Moelok, 2018).

Data Badan Koordinasi Penanaman Modal (BKPM) menunjukkan adanya optimisme terhadap industri kesehatan. BKPM (2020) menyebutkan bahwa di semester I tahun 2020, dari total 112.862 permohonan ijin, sejumlah 16.286 adalah permohonan ijin operasional di sektor kesehatan (BKPM, 2020).

Salah satu strategi dalam beradaptasi terhadap era revolusi industri 4.0 adalah peningkatan kualitas sumber daya manusia agar memiliki keunggulan kompetitif. Pengelolaan dan pembinaan sumber daya manusia menjadi strategi agar menghasilkan keunggulan komparatif (Ismajli, et.al., 2015).

Di sektor kesehatan perawat meenjadi garda terdepan dalam kualitas pelayanan di rumah sakit. Kompetensi perawat bisa ditempatkan dimana saja, sehingga profesionalitas kerja serta kemampuan team work sangat dibutuhkan. Sebagai helping profession, perawat harus memiliki self compassion dan altruisme (Dewi \& Hidayati, 2015).

Menurut Hartiti \& Shaumayantika (2018) perawat yang kompeten harus memiliki nilainilai profesionalitas yaitu martabat diri manusia, altruism, otonomi, integritas, dan keadilan. Peningkatan kompetensi perawat dimaksudkan agar memiliki daya saing (Arisanova \& Satyawan, 2017).

Lulusan perawat yang memiliki daya saing diharapkan akan dapat beradaptasi dengan era industri 4.0 yang memiliki ciri khas akan pesatnya perkembangan teknologi dan informasi. Menurut Lestari (2014) perawat yang memiliki daya saing dalam taraf internasional adalah perawat yang profesionalitasnya dilengkapi aspek intelektual, interpersonal, tehnikal, peka akan perbedaan sosial budaya, serta mampu memanfaatkan ilmu pengetahuan dan teknologi.

Penerapan nilai profesionalisme perawat diajarkan sejak di perguruan tinggi dalam pembelajaran maupun praktek keperawatan (Hartiti \& Shaumayantika, 2018). Nilai profesionalisme perawat identik dengan kualitas pelayanan yang sesuai dengan standar profesi keperawatan (Lestari, 2014).

Perawat diharapkan mampu memberikan pelayanan yang berkualitas sebagai bentuk tanggung jawab profesi (Majid \& Sani, 2016). Menyadari bahwa kualitas lulusan perawat dipengaruhi oleh prestasi belajar dan pemahaman terhadap proses belajar (Prihatmoko, 2015), maka diperlukan pembinaan bagi calon perawat melalui pendidikan maupun training.

Kendati berbagai upaya telah dilakukan oleh Sekolah Tinggi Keperawatan (STIKES BHAKTI) Al Qodiri untuk melakukan pembinaan terhadap mahasiswa perawat, namun masih dirasakan kekurangan dalam hal motivasi dan pemahaman akan manajemen karir perawat. Mahasiswa belum memiliki optimisme akan karir sebagai perawat.

Permasalahan ini menjadi krusial, karena penurunan motivasi ini berimbas pada penurunan prestasi belajar, hingga mengundurkan diri dari perkuliahan. Hal ini mahasiswa belum memahami tentang manajemen karir nantinya dan kurangnya motivasi belajar. Pemilihan karir didasarkan bukan karena pengetahuan tentang manajemen karir, yang berakibat pada antusiasme dalam belajar yang rendah.

Padahal optimisme positif dapat membangun motivasi dan harapan individu terhadap masa depannya (Riziq \& Musabiq, 2015). Dengan optmisme akan pilihan karirnya, mahasiswa akan berusaha bangkit manakala terjadi kegagalan, cenderung aktif, tidak putus harapan dan memiliki perencanaan (Rahmalia \& Frieda).

Dari gambaran analisis situasi dan permasalahan di Sekolah Tinggi Keperawatan (STIKES BHAKTI Al Qodiri) Jember tersebut, maka perlu dilaksanakan training yang menarik mengingat waktu yang cukup lama yaitu 6 bulan. Training juga perlu 
didukung materi yang sesuai dengan kebutuhan sehinggga mampu meningkatkan pengetahuan dan motivasi mahasiswa perawat. Program Training Personality Development menjadi solusi yang ditawarkan yang memadukan antara materi serta strategi training

\section{KAJIAN LITERATUR DAN PENGEMBANGAN HIPOTESIS}

\section{Training Personality Development}

Training merupakan proses yang sistematis guna mendapatkan pengetahuan, mengembangkan keterampilan teknis dan mendapatkan perubahan sikap (Majid \& Sani, 2016; Sinambela, 2018). Tujuan dari training adalah perubahan perilaku serta peningkatan pengetahuan dan pemahaman. Karena dalam training terdapat upaya membangun kebiasaan menjadi lebih baik, serta membentuk cara pandang dan sikap yang lebih baik (Saleh, 2016).

Untuk mendapatkan pengetahuan dan pemahaman profesionalitas dalam bekerja, maka diperlukan kombinasi antara pendidikan dari perguruan tinggi dengan program training. Sebab desain training yang sesuai dengan proses pembelajaran (pendidikan) akan berkontribusi terhadap daya saing (Sinambela, 2018).

Pelatihan atau training terbukti mampu meningkatkan kinerja perawat, hal ini ditunjukkan pada peneltian (Majid \& Sani, 2016; Ernawati, 2012). Pelatihan juga mampu meningkatkan kualitas pelayanan dan profesionalisme perawat, hal ini dibuktikan pada penelitian (Kusmiran, 2017 ; Ningsih, 2014 ).

Menurut Sinambela (2018) desain pelatihan yang sistematis adalah yang sesuai dengam kebutuhan dan tujuan pelatihan. Efektivitas pelatihan tergantung pada akurasi dan metode yang diberikan (Saleh, 2016). Pelatihan akan memberikan kontribusi terhadap peningkatan kinerja dan efisiensi dana apabila menggunakan Materi dan Metode yang sesuai dengan kondisi aktual (Jambak, 2006 ; Firdaus \& Hasanah, 2017).

Pelaksanaan pengabdian masyarakat ini dilakukan dengan menggunakan program
Training Personality Development. Sesuai dengan kebutuhan dan tujuan training, maka desain training dengan memadukan antara materi dan metode training.

\section{Optimisme Karir}

Dalam beberapa kajian, optmisme didefinisikan sebagai karakteristik dasar pada diri individi untuk meyakini dan memiliki dasar pemikiran yang optmis (Riziq \& Musabiq, 2015; Sabiq \& Miftahuddin, 2017). Optimisme juga diartikan sebagai padangan menyeluruh yang membuat individu mampu berfikir positif, melihat dari sudut pandang positif (Ramadhani, 2014).

Perasaan optimis akan membawa individu pada keyakinan (self effication) akan kemampuan merealisasikan pilihan karirnya serta percaya diri (Prayitno \& Ayu, 2017) serta memiliki harapan akan berjalan menuju kebaikan (Safarina, Munir, \& Nur'aini, 2019). Individu yang memahami dan optimis pada pilihan karirnya memperlihatkan sikap optimistik : permanence, pervasiveness, serta personalization (Ramadhani, 2014).

Prayitno \& Ayu (2017) mengemukakan bahwa individu yang memiliki optimisme karir memperlihatkan sikap yang optimis untuk meraih masa depan karirnya, tidak mudah menyerah, mempunyai harapan baik, dan berfikir positif. Dari berbagai pendapat tersebut, maka indikator yang digunakan pada variabel optimisme karir adalah optimis akan prospek karirnya, percaya diri serta memiliki harapan positif.

\section{METODE PELAKSANAAN}

Pelaksanaan program pengabdian masyarakat ini diawali dengan menjalin kemitraan Sekolah Tinggi Ilmu Kesehatan Bhakti Al Qodiri yang berada dalam naungan Pondok Pesantren (PP) Al Qodiri. Kemitraan dijalin dengan 2 program studi yaitu Program Studi Keperawan (S1) dan Program Studi Kebidanan (D3). Melihat permasalahan mahasiswa serta urgensi penanganan, maka kegiatan pengabdian dikhususkan terlebih dahulu kepada mahasiswa Program Studi Keperawan.

Hasil observasi dan wawancara memberikan gambaran akan kondisi riil dan permasalahan di sekolah tinggi keperawatan. 
Kondisi riil di tempat pelaksanaan program pengabdian masyarakat ini di sekolah tinggi perawat yang berintegrasi dengan pondok pesantren. Karenanya pembinaan di sekolah tinggi keperawatan (STIKES) diarahkan kepada pengembangan nilai spiritual islam melalui kegiatan-kegiatan di kampus dan di pondok pesantren.

Pelaksanaan pengabdian masyarakat yaitu program training personality development mulai dilaksanakan 7 Maret 2020 hingga tanggal 20 Maret 2020. Namun rencana program yang telah disusun mengalami perubahan dikarenakan kondisi Pandemi Covid 19, sehingga pertemuan kemudian diubah menjadi pertemuan daring sejak tanggal 26 Maret 2020.

Sasaran training adalah mahasiswa perawat di STIKES BHAKTI Al Qodiri Jember, yang sedang mempersiapkan diri untuk praktikum di Rumah sakit. Hal ini merupakan hasil diskusi dan kesepakatan bersama dengan ketua dosen dan ketua program studi Keperawatan. Mengingat urgensi permasalahannya serta tujuan training, maka peserta training atau trainee adalah (1) Mahasiswa yang mengikuti training adalah yang tinggal di pondok pesantren. (2) Mahasiswa yang mengikuti adalah mahasiswa semester 4 karena mahasiswa telah mendapatkan pengetahuan teoritik tentang keperawatan dan sedang dipersiapkan untuk praktikum. Dari kriteria tersebut diperoleh 30 mahasiswa yang akan mendapatkan Training personality development programme.

Metode pelatihan adalah berbagai cara atau model pelatihan yang digunakan untuk mentransfer keterampilan dan pengetahuan selama proses pelatihan (Sinambela, 2018). Metode training yang partisipatif akan menarik minat trainee (Firdaus \& Hasanah, 2017). Maka kegiatan pelaksanaan pengabdian masyarakat ini dilakukan melalui lima tahapan. Berikut merupakan tahapan kegiatan pelaksanaan pengabdian masyarakat antara lain : (1) Identifikasi kebutuhan program training; (2) Penetapan tujuan training; (3) Merancang program training (4) Pelaksanaan program training (5) Evaluasi dan monitoring.

1) Tahap Pertama : Identifikasi Kebutuhan Training. Tahapan awal pelaksanaan penelitian adalah mengidentifikasi kebutuhan training. Training akan berhasil apabila memenuhi kebutuhan akan kekurangan pengetahuan, mampu meningkatkan keterampilan dan perubahan sikap menjadi lebih baik (Zainal, et.al, 2014). Dari hasil studi pendahuluan dan diskusi bersama ketua program studi keperawatan maka diperoleh gambaran akan permasalahan dan kebutuhan training yang diharapkan dapat menjadi solusi bagi peserta training yaitu mahasiswa.

2) Tahap Kedua : Penetapan tujuan training. Ini dilakukan setelah diperoleh gambaran permasalahan serta solusi yang akan dilakukan. Agar pelatihan lebih terarah maka ditetapkan tujuan training personality development antara lain: memberikan pemahaman tentang kebutuhan dunia kerja khususnya profesi perawat, memotivasi mahasiswa agar tumbuh optimisme dalam pilihan karirnya sebagai perawat serta tumbuhnya pemahaman akan kepribadiannya dan kesadaran pengembangan diri.

3) Tahapan Ketiga : Tahapan perancangan program training. Pada tahapan ini ditetapkan waktu kegiatan, lama kegiatan, tujuan dan target. Training personality development dilakukan selama 6 bulan dengan pertemuan satu kali dalam seminggu. Di tahapan ini responden diberikan kuisioner guna menganalisis semangat serta motivasi belajar mahasiswa.

Metode yang rencananya akan digunakan dalam Training Personality Development adalah Simulasi, Ceramah, Pemutaran Video, Studi Kasus, Personality Test, Diskusi, dan Role Play/Game. Materi yang akan diberikan dalam training terdiri dari lima tema antara lain : Manajemen waktu dalam dunia kerja; Motivasi Kerja dan Motivasi Berprestasi; Pengembangan Kepribadian, Persepsi dan komunikasi; Empati, perilaku asertif dan kerja sama; Manajemen konflik

4) Tahapan Keempat : Tahapan pelaksanaan. Training personality development dimulai tanggal 7 Maret 2020. Training dibuka dengan tema Pengembangan Diri dan Manajemen Karir, 
menggunakan metode pemutaran video, ceramah, simulasi games, personality test dan konseling. Selama proses training, mahasiswa nampak antusias mengikuti, terutama pada sesi personality test, games, dan konseling klasikal. Hal ini nampak dari hasil diskusi yang terjadi, serta antusiasme dalam merespon dan mengikuti kegiatan.

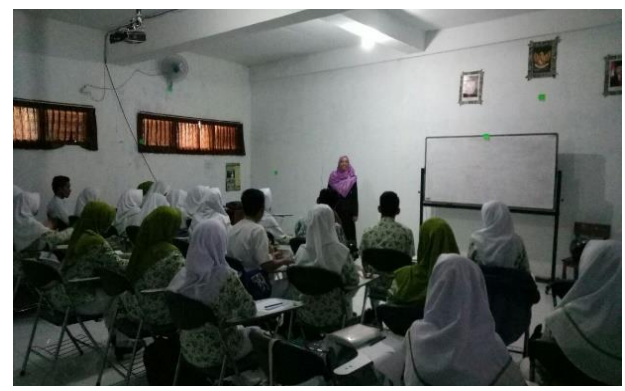

Gambar 1. Metode ceramah dalam training personality development

Namun kendala Pandemi Covid19, menyebabkan perubahan menjadi pertemuan daring sejak tanggal 26 Maret 2020. Media training berubah, menggunakan google classroom, zoom meeting, whatapp grup. Metode yang bisa dilakukan selama pelatihan secara daring ini adalah ceramah, diskusi, studi kasus, serta konseling individual, baik melalui zoom meeting maupun google classroom.

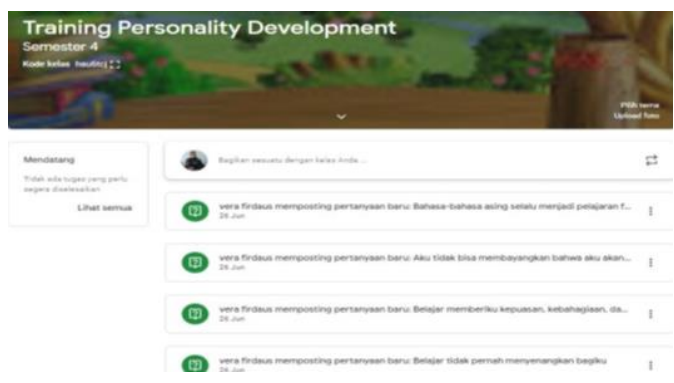

Gambar 2. Screenshoot google classroom

Kegiatan diakhiri dengan pemberian kuis sebagai bahan evaluasi.

5) Tahapan Kelima adalah Evaluasi dan monitoring. Hasil evaluasi menjadi jawaban akan efektifitas training personality development bagi calon perawat. Pelaksanaan pengabdian ini tetap mendapatkan monitoring dari sekolah tinggi keperawatan. Respon yang baik diberikan oleh pihak penyelenggara dengan harapan training personality development programme ini akan dilanjutkan pada tahun berikutnya.

\section{HASIL DAN PEMBAHASAN}

Hasil kegiatan pengabdian masyarakat ini adalah ketercapaian tujuan training yaitu pemahaman calon perawat (mahasiswa) tentang prospek karir perawat sehingga tumbuh optimisme akan pilihan karirnya, menumbuhkan kesadaran akan pengembangan kepribadian diri.

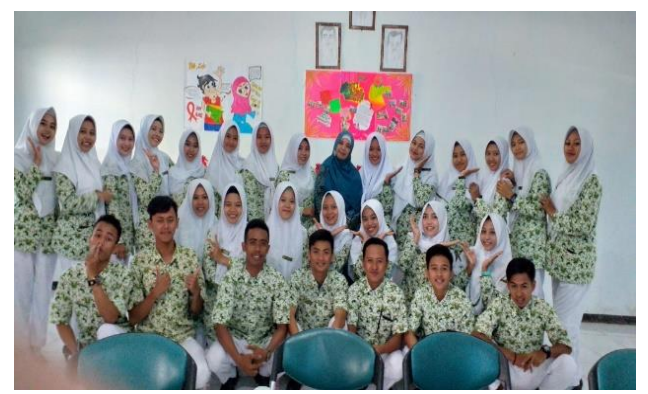

Gambar 3. Peserta training personality development

Dari hasil kuis yang dibagikan saat kegiatan, mahasiswa telah memahami akan tujuan pilihan karirnya sebagai perawat. Mahasiswa juga mulai bisa memahami kelemahan dan kelebihan diri agar dapat mengoptimalkan dan mengevaluasi diri. Mahasiswa juga mengetahui prospek karir sebagai perawat.

Pengabdian masyarakat melalui training personality development yang dilaksanakan mulai 7 Maret 2020 dan training terakhir pada tanggal 20 Maret 2020 memiliki perbedaan hasil pemahaman pada mahasiswa atau peserta training. Ketika mahasiswa diberikan pertanyaan tentang pelaksanaan training, mahasiswa nampak lebih antusias dan lebih memahami materi pada saat training secara offline. Metode dan materi yang disampaikan dengan tatap muka lebih dirasakan optimal oleh mahasiswa. Hal ini karena komunikasi yang lebih intensif serta lebih variatif dalam metode training. Sedangkan training yang dilakukan secara daring dianggap mahsiswa kurang optimal dikarenakan komunikasi yang terbatas dan tidak ada simulasi dan role game.

Hasil pengabdian masyarakat ini direspon dengan baik oleh mitra pengabdian. Hal ini dibuktikan dengan kerja sama yang masih akan dilanjutkan. Luaran pengabdian 
masyarakat ini adalah publikasi hasil pengabdian pada jurnal pengabdian masyarakat, makalah yang disampaikan dalam seminar pengabdian masyarakat serta modul pengembangan kepribadian.

\section{KESIMPULAN}

Dalam menghadapi era industri 4.0, diperlukan peningkatan kompetensi. Perawat yang berkompeten adalah yang memiliki nilainilai profesionalitas yaitu altruism, integritas, dan self compassion serta pengembangan kepribadian diri. Pengabdian masyarakat melalui Training Personality Development telah memberikan pemahaman akan prospek karir sebagai perawat, dan pemahaman tentang kebutuhan dunia kerja. Kegiatan training juga telah memberikan optimisme bagi calon perawat (mahasiswa) akan pilihan karirnya sebagai perawat dan kesadaran akan pengembangan kepribadiannya agar dapat menjadi perawat yang profesional.

\section{REFERENSI}

Arisanova, M. D., \& Satyawan, A. (2017). Peningkatan Daya Saing Indonesia di Bidang Keperawatan melalui Implementasi Indonesia-Japan Economic Partnership Agreement (IJEPA) tahun 2008-2013. Program Studi Hubungan Internasional, Fakultas Ilmu Sosial dan Politik. Surakarta: Universitas Sebelas Maret. Retrieved 2017

BKPM. (2020). Domestic And Foreign Direct Investment Realization Quarter IV And January - December 2019. Badan Koordinasi Penanaman Modal (BKPM). Jakarta: The Investment Coordinating Board of the Republic of Indonesia. Retrieved Januari 29, 2020

Dewi, S. R., \& Hidayati, F. (2015). Selfcompassion Dan Altruisme Pada Perawat Rawat Inap RSUD Kota Salatiga. Jurnal Empati, 4, 168-172. Retrieved Januari 2015

Ernawati, S. U. (2012). Pengaruh Pelatihan Terhadap Kinerja Perawat Dengan Motivasi Sebagai Variabel Moderasi (Studi Pada RSUD Dr. Saiful Anwar Malang). Jurnal Pendidikan Biologi
Indonesia, 2, 111-122. Retrieved Oktober 2012

Firdaus \& Hasanah. (2017). Desain Training Guru Paud Melalui Analisis Kebutuhan Training Untuk Meningkatkan Kinerja Guru PAUD. Seminar Nasional Penguatan Kualitas Pendidikan Tinggi Melalui Publikasi Ilmiah Bereputasi (pp. 216-224). Madiun: LPPM Unipma Madiun. Retrieved Oktober 5, 2017

Firdaus, V., \& Hasanah, H. (2017). Pengaruh In The Job Training Dan Off The Job Training Terhadap Peningkatan Kinerja Guru PAUD. Fenomena, 16. Retrieved Oktober 2017

Hartiti, T., \& Shaumayantika, N. (2018). Nilai Profesional Keperawatan Pada Mahasiswa Ners. Jurnal Keperawatan, 10, 94 - 101. Retrieved September 2018

Jambak, A. (2006). Analisis Kebutuhan Pelatihan Karyawan Pada Tingkat Supervisor Di PT. Jakaranatama Kantor Ciawi, Kabupaten Bogor. Tesis. Program Studi Manajemen Agribisnis,Fakultas Pertanian Institut Pertanian Bogor. Tesis, Fakultas Pertanian Institut Pertanian Bogor, Program Studi Manajemen.

Kusmiran, E. (2017). Pelatihan Soft Skills Caring Meningkatkan Kualitas Pelayanan Keperawatan dan Kepuasan Pasien di Rumah Sakit Kota Bandung. Jurnal Penelitian dan Pengembangan Pelayanan Kesehatan, 1, 72-81. Retrieved Desember 2017

Lestari, T. R. (2014). Pendidikan Keperawatan: Upaya Menghasilkan Tenaga Perawat Berkualitas. Aspirasi, Jurnal Masalah-masalah Sosial, 5, 110. Retrieved Juni 2014

Majid, A., \& Sani, A. (2016). Pengaruh Pelatihan Dan Supervisi Kepala Ruangan Terhadap Kinerja Perawat Pelaksana Diruang Rawat Inap Bedah Rumah Sakit Tk. Ii Pelamonia Makassar. Jurnal Mirai Management, 1, 310-412. Retrieved Oktober 2016 
Moelok, N. F. (2018, April 25). Peran Industri Kesehatan Dalam Mendukung Laju Pertumbuhan Ekonomi Di Indonesia. Retrieved from Seminar Nasional IV Peran Industri Kesehatan Dalam Mendukung Pertumbuhan Ekonomi Di Indonesia.

Prayitno, S. H., \& Ayu, M. S. (2017). Hubungan Optimisme Masa Depan Dan Motivasi Berprestasi Terhadap Prestasi Belajar Mata Ajar Bahasa Inggris Mahasiswa Semester 1 Prodi Diii Keperawatan Rustida Tahun Ajaran 2016-2017. Jurnal Insight Fakultas Psikologi Universitas Muhammadiyah Jember, 13, 80-95. Retrieved Oktober 2017

Prihatmoko, I. g. (2015). Hubungan Antara Gaya Berpikir Dan Gaya Belajar Dengan Pencapaian Indeks Prestasi Semester I Mahasiswa Akademi Keperawatan Panti Rapih Yogyakarta Tahun Akademik 2013/2014. Jurnal AKPER Panti Rapih, 1, 45-58. Retrieved Januari 2015

Rahmalia, A., \& Frieda, N. (n.d.). Self Esteem Dan Optimisme Raih Kesuksesan Karir Pada Fresh Graduate Fakultas Teknik Universitas Diponegoro. Jurnal Empati, 4, 15-19. Retrieved Oktober 2015

Ramadhani, R. (2014). Hubungan Antara Optimisme Dan Dukungan Sosial Dengan Coping Stress Pada Mahasiswa Keperawatan Yang Sedang Menyusun Skripsi Di STIKES Muhammadiyah Samarinda. Jurnal Motivasi.

Riziq, F., \& Musabiq, S. (2015). Optimisme dan Efikasi Diri Pengambilan Keputusan Karir Pada Mahasiswa Program Diploma III Kebidanan. Jurnal Ilmu Kebidanan, 3, 137-151. doi: 10.000000

Safarina, Munir, A., \& Nur'aini. (2019). Hubungan Harga Diri dan Optimisme Dengan Kesejahteraan Subjektif Pada Mahasiswa Magister Psikologi Universitas Medan Area. Tabularasa: Jurnal Ilmiah Magister Psikologi, 1,
39-48.

doi:https://doi.org/10.31289/tabularasa .vli1

Saleh, A. (2016). Manajemen Training : Teknik Praktis Pengelolaan training Dan Pelatihan Sumber Daya (Cetakan Pertama ed.). Malang: Universitas Brawijaya Press.

Sinambela, L. P. (2018). Manajemen Sumber Daya Manusia, Membangun Tim Kerja Yang Solid Untuk Meningkatkan Kinerja. Jakarta: PT Bumi Aksara. Retrieved Januari 2018 